\title{
OS GÊNEROS TEXTUAIS E A TIPOLOGIA INJUNTIVA
}

Vanilda Salton KÖCHE Adiane Fogali MARINELLO Odete Maria Benetti BOFF 1

É consenso entre os teóricos que um ensino eficiente de língua materna pressupõe um trabalho com o texto. Geraldi (1993), um dos grandes estudiosos do ensino de língua portuguesa no Brasil, é enfático ao afirmar que a produção de textos, quer orais ou escritos, é ponto de partida e ponto de chegada de todo o processo de ensino-aprendizagem. Isso decorre do fato de a materialização dos textos acontecer nas situações sociais do dia-a-dia, na forma de gêneros textuais. Nessa perspectiva, os Parâmetros Curriculares Nacionais (1999) recomendam o trabalho com o texto e consideram a função social dos gêneros, aproximando realidade social e ensino de língua. Sugerem ainda que o professor explore as tipologias textuais no interior de cada gênero. Assim, o ensino de língua materna, metodologicamente situado na leitura, compreensão, análise e produção de gêneros textuais, desponta como um importante caminho para auxiliar no desenvolvimento da competência comunicativa dos alunos.

Este artigo apresenta uma discussão sobre gêneros e tipologias textuais, aborda a tipologia injuntiva e analisa dois gêneros em que essa tipologia predomina: um manual de instruções e uma receita culinária. Este estudo é significativo, pois textos injuntivos fazem parte do cotidiano do aluno e estão presentes nos diversos ambientes discursivos da sociedade. Os Parâmetros Curriculares Nacionais (1999) e os teóricos Bakhtin (1992), Adam (1992), Bronckart (1999), Fávero e Koch (1998), Geraldi (1993), Marcuschi (2002), Rosa (2003), Travaglia (1991), Schneuwly, Dolz e colaboradores (2004) fundamentam este trabalho.

1. UCS-CARVI. 


\section{Os gêneros textuais e as tipologias textuais}

Toda a atividade comunicativa ocorre através dos gêneros textuais, o que justifica a multiplicidade dos gêneros. Para Bakhtin (1992), "se não existissem os gêneros do discurso e se não os dominássemos, se tivéssemos de criá-los pela primeira vez no processo da fala, se tivéssemos de construir cada um de nossos enunciados, a comunicação verbal seria quase impossível" (p.302). Portanto, os gêneros exercem uma função fundamental nas relações entre os sujeitos, visto que a língua é concebida como uma atividade social, histórica e cognitiva.

Nesse sentido, para Bronckart (1999), “a apropriação dos gêneros é um mecanismo fundamental de socialização, de inserção prática nas atividades comunicativas humanas" (p.103). O trabalho com gêneros textuais permite, portanto, que o sujeito se torne o autor de seu dizer e possa estar inserido em seu contexto social e histórico. Alguns exemplos de gêneros textuais são: carta pessoal, receita culinária, manual de instruções, bula de remédio, romance, conto, reportagem, notícia jornalística, editorial, resumo, resenha, esquema, redação de vestibular, edital de concurso, inquérito policial, piada, cardápio de restaurante, sermão, conferência, aula expositiva, conversação e reunião de condomínio.

Bakhtin (1992) define os gêneros do discurso como tipos relativamente estáveis de enunciados produzidos pelas mais diversas esferas da atividade humana (Cf. BAKHTIN: 1992, p.279). Isso significa que eles podem ser modificados, dependendo da situação sócio-comunicativa em que são empregados.

Por sua vez, numa escala sócio-histórica, Bronckart (1999) afirma que: os textos são produto da linguagem em funcionamento permanente nas formações sociais: em função de seus objetivos, interesses e questões específicas, essas formações elaboram diferentes espécies de textos, que apresentam características relativamente estáveis (justificando-se que 
sejam chamadas de gêneros de texto) e que ficam disponíveis no intertexto como modelos indexados para os contemporâneos e para as gerações posteriores. (p.137)

Marcuschi (2002) define os gêneros como eventos textuais altamente maleáveis, dinâmicos e plásticos, que surgem das necessidades e atividades socioculturais e na relação com inovações tecnológicas, que motivam a explosão de novos gêneros e novas formas de comunicação, quer na oralidade, quer na escrita (p.19). Entre essas inovações, destacamos os gêneros blog, chat, e-mail e teleconferência. Os gêneros textuais, portanto, resultam do contexto cultural em que se originam e se desenvolvem.

Para o referido autor, os gêneros ordenam e estabilizam as atividades comunicativas do dia-a-dia e podem se expressar em diversas designações, sendo possível mesmo dizer que são ilimitados (Cf. MARCUSCHI: 2002, p.19-23). Por exemplo, uma dissertação de mestrado é produzida com o intuito de o indivíduo alcançar o título de mestre; uma redação de vestibular serve para um candidato disputar uma vaga em um curso superior e um anúncio publicitário objetiva promover a venda de determinado produto ou serviço.

O gênero textual, de modo geral, é heterogêneo, visto que, na maioria das vezes, contém diferentes sequências tipológicas na sua estrutura. Exemplificamos: uma carta pessoal pode apresentar sequências narrativas, argumentativas, descritivas, preditivas, explicativas ou injuntivas. Assim, embora a carta pessoal, normalmente, tenha um caráter narrativo, pode conter diferentes tipologias textuais.

Marcuschi (2002) conceitua tipo textual como uma espécie de sequência teoricamente definida pela natureza linguística de sua composição (aspectos lexicais, sintáticos, tempos verbais, relações lógicas, estilo). Constata-se, desse modo, que a distinção entre as tipologias textuais 
tem por base as diferenças linguísticas, e o que distingue os gêneros são os aspectos funcionais.

O conjunto das tipologias textuais é limitado e não tende a aumentar, ao passo que o número de gêneros é ilimitado, com tendência a ser ampliado no transcorrer do tempo. As tipologias dão suporte na composição de um gênero. Assim, quando certa tipologia textual predomina num determinado texto concreto, dizemos que esse é um texto argumentativo, narrativo, descritivo, injuntivo, dialogal, prescritivo, entre outros.

\section{Tipologia textual injuntiva}

A tipologia textual injuntiva caracteriza-se por guiar os indivíduos para a execução de uma atividade específica e/ou estabelecer normas para direcionar as práticas sociais. É frequentemente encontrada nos gêneros textuais que circulam no cotidiano de qualquer indivíduo. Por exemplo, uma dona de casa, ao folhear o seu livro de receitas culinárias, depara-se com inúmeros textos injuntivos que visam a orientá-la no preparo de alimentos.

A injunção está presente também em gêneros como os manuais e as instruções de uso e montagem, os textos de orientação (leis de trânsito, recomendações de trânsito e direção), os regulamentos, as regras de jogo, os regimentos, as leis, os decretos, os textos que ensinam a confeccionar trabalhos manuais e objetos para o lar, as bulas de remédios, os textos doutrinários e as propagandas. Eles podem ser publicados em cartazes, revistas, panfletos, embalagens de produtos, correspondências, entre outros suportes. Segundo Travaglia (1991), essa tipologia abrange ainda a optação, que se constitui no discurso da manifestação do desejo; nesta circunstância, o locutor não tem controle sobre a concretização da situação - "Que Deus te ajude!" (p.50).

De acordo com Bronckart (1999), a opção pela sequência injun- 
tiva para compor um gênero textual implica o objetivo de querer "fazer agir" o interlocutor numa direção específica, apontada pelo texto. A ação, portanto, visa diretamente ao interlocutor.

A injunção, conforme Travaglia (1991), almeja incitar à realização de uma situação (ação, fato, fenômeno, estado, evento etc.), requerendo-a ou desejando-a, ensinando ou não como realizá-la. A informação diz respeito a algo a ser feito ou como deve ser feito. Fica a cargo do interlocutor executar aquilo que se solicita ou se define que seja feito, em uma ocasião posterior ao momento da enunciação (Cf. TRAVAGLIA: 1991, p.50). Está ligada, portanto, a comportamentos futuros.

Na mesma linha de raciocínio, Rosa (2003) afirma que o produtor pode utilizar os textos injuntivos com várias finalidades: aconselhar o interlocutor a fazer algo, ordenar-lhe que cumpra determinadas tarefas, apelar para que aja numa determinada direção, instruí-lo, ensiná-lo a desenvolver uma atividade, entre outras (Cf. ROSA: 2003, p.25).

Adam (1992) agrupa os gêneros de base injuntiva sob a denominação de gêneros textuais de sequencialidade injuntiva-instrucional. Segundo o autor, esses gêneros buscam induzir atos e tratam explicitamente de um fazer prático, de um agir-saber sobre o mundo. Por isso, caracterizam-se por apresentar uma estrutura linear ordenada temporalmente, constituída por uma sucessão lógica ou cronológica de fases ou etapas de um comportamento ou processo a executar, recomendando ao interlocutor seguir rigorosamente as indicações.

Nessa perspectiva, a partir das capacidades de linguagem dominantes dos sujeitos, Schneuwly, Dolz e colaboradores (2004) incluem os gêneros textuais em que predomina a injunção na ordem do "descrever ações" ou "instruir/prescrever ações". Os autores destacam que essa ordem diz respeito às normas que devem ser seguidas para atingir algum objetivo (instruções e prescrições) (Cf. SCHNEUWLY, DOLZ e colab.: 
2004: p.60-61).

O mecanismo linguístico mais empregado para indicar a concretização desses enunciados que incitam à ação são os verbos no modo imperativo, que podem aparecer também de forma implícita. Entretanto, esse não é o único recurso utilizado, pois orações com verbos modais (dever, ter que), verbos no futuro do presente (colocará, deverá, será) e no infinitivo (mexer, juntar, acrescentar) também são muito comuns.

Geralmente, os gêneros textuais com tipologia de base injuntiva empregam períodos simples e curtos, pois construções extensas podem prejudicar a clareza das orientações. Utilizam ainda operadores argumentativos apropriados ao encadeamento sequencial das ações.

Como os textos injuntivos são produzidos para um público que tanto pode ser masculino quanto feminino, jovem ou adulto, o enunciador mantém certa neutralidade no tratamento. Muitas vezes, utiliza o pronome você para se dirigir ao leitor, como nos manuais de instruções e regras de jogos. Porém, na maioria dos casos, o pronome está implícito e a terminação verbal garante esse entendimento.

Como se observa, a injunção se caracteriza por estabelecer um processo de interação que compreende emissor, texto e receptor. O enunciador elabora comandos e/ou sugere a adoção de atitudes ou comportamentos, transmitindo conhecimentos de forma sistematizada, na perspectiva de que o interlocutor concretize uma situação específica, pois o considera apto para isso. Nesse sentido, Bronckart (1999) destaca que as sequências têm um estatuto basicamente dialógico, uma vez que se fundamentam em decisões interativas (Cf. BRONCKART: 1999, p.234).

Nos textos em que prevalece a tipologia textual injuntiva, a linguagem tem uma função social específica, pois, segundo Rosa (2003), "é usada por um produtor em razão de permitir ao seu interlocutor executar ou adquirir um conhecimento sobre como executar uma determi- 
nada tarefa" (p.15). Conforme a autora, o "fazer agir" comunicado no texto está relacionado ao "dizer como fazer" do produtor, um "dizer" que está divulgado de forma explícita. O destinatário, geralmente, sabe que o texto injuntivo o conduzirá através de uma sequência programada de microações a concluir uma macroação, que almeja ou está incumbido de efetuar (Cf. ROSA: 2003, p.32).

Num texto que ensina a confeccionar um origami, por exemplo, tem-se uma macroação a ser realizada: produzir a dobradura de um barquinho de papel. Para efetuá-la, é necessário que o leitor execute uma série de microações, explicitadas no texto. Elas estão relacionadas ao tipo e tamanho do papel e aos passos que precisam ser seguidos para, a partir de um pedaço de papel - a situação inicial -, chegar à figura do barco - o produto final.

Conforme Rosa (2003), a tipologia textual injuntiva compõe-se de três etapas básicas. A primeira denomina-se "exposição do macro-objetivo acional" - refere-se à indicação de um objetivo geral a ser atingido pelo leitor. A fase seguinte chama-se "apresentação dos comandos" - diz respeito à exposição de uma sequência de ações, estabelecida pelo produtor, a ser executada para a concretização do macro-objetivo acional. A última etapa denomina-se "justificativa" - contempla a explicitação, por parte do produtor do texto, das razões pelas quais o destinatário deve seguir o(s) comando(s) estabelecido(s). Segundo a autora, essa fase tem a sua aparição mais restrita na tipologia textual injuntiva e sua explicitação resultam de uma decisão do produtor do texto. Sua presença é bastante comum nos textos de conselho e muito reduzida em leis e regimentos, pois nesses gêneros os comandos são vistos como obrigatórios e inquestionáveis.

Nesse sentido, Adam (1992) destaca que os gêneros textuais de sequencialidade injuntiva-instrucional subentendem dois estados, "o de 
partida" (ou inicial) e "o de chegada" (ou final), e aponta a existência de "um núcleo transformacional". Ele exemplifica com a apresentação do gênero receita culinária: temos, de um lado, a lista dos ingredientes e, de outro, frequentemente, a foto do prato pronto, que constitui a atualização icônica da receita propriamente dita; o núcleo transformacional garante a passagem dos ingredientes não preparados ao prato concluído.

Como se observa, o estado final origina-se de um macro-objetivo acional e decorre da execução de um plano de ação por parte do interlocutor que propiciou a transformação de um estado inicial.

Geralmente, os textos injuntivos constituem sequências textuais específicas que assinalam imposição, ordem, indicação, sugestão ou conselho. Por exemplo, no Código de Defesa do Consumidor (BRASIL, lei $\mathrm{n}^{\mathrm{o}} 8.078$, de 11 de setembro de 1990), o receptor se verá forçado a realizar as ações indicadas no texto: "o fornecedor não poderá colocar no mercado de consumo produto ou serviço que sabe ou deveria saber apresentar alto grau de nocividade ou periculosidade à saúde ou segurança". Caso o interlocutor não tome as atitudes apontadas, estará sujeito à punição de acordo com o que define a legislação.

Nesse código, o produtor do texto utiliza a injunção com o caráter discursivo de ordem. Ele representa um órgão do governo e se encontra em um nível hierarquicamente superior, o que lhe dá respaldo diante de seu interlocutor para determinar como deve agir. O produtor está legitimado socialmente, e isso garante que a interação tenha sucesso.

Por outro lado, existem textos injuntivos em que o produtor não usa a injunção na perspectiva de uma ordem. Por exemplo, numa receita culinária, o interlocutor não necessita obrigatoriamente seguir todos os comandos apresentados no gênero, exceto queira. Determinadas instruções aparecem como sugestão. Além disso, se desejar, o leitor poderá acrescentar ingredientes que não estão indicados no texto ou modificar as 
quantidades, sabendo que suas escolhas repercutirão no produto final.

Segundo Rosa (2003), os comandos propostos nos textos injuntivos podem ser obrigatórios ou opcionais. A execução dos comandos obrigatórios é imprescindível para que o macro-objetivo acional seja atingido. Já os opcionais estão ligados a uma escolha do interlocutor do texto, e sua execução não é pré-requisito para a concretização do macro-objetivo (Cf. ROSA: 2003, p.43).

Rosa (2003) apresenta um agrupamento preliminar dos textos injuntivos, considerando a função sócio-comunicativa de cada gênero (Cf. ROSA: 2003, p.32). Assim, agrupa-os nas seguintes categorias:

a) textos instrucionais-programadores: tem por finalidade instruir/ensinar alguém a realizar algo (exemplos: receitas, guias e manuais de um modo geral);

b) textos de conselho: objetivam aconselhar alguém a fazer algo (exemplos: horóscopo e conselhos de saúde, beleza, comportamento etc.);

c) textos reguladores-prescritivos: visam a obrigar alguém a efetuar algo (exemplos: ordens, leis, regimentos, regras de jogos).

Como se observa, os gêneros textuais de base injuntiva podem ser utilizados com diversos propósitos no dia-a-dia. Constituem, portanto, um conjunto aberto e não são passíveis de classificações definitivas.

\section{Gêneros textuais com tipologia textual de base injuntiva}

Apresentaremos, nesta parte, uma análise de dois gêneros textuais de base injuntiva: um manual de instruções e uma receita culinária.

No primeiro texto, as denominações originais do produto e de seu respectivo fabricante foram substituídas por nomes fictícios para preservar os direitos autorais. 


\subsection{Manual de instruções}

\section{SUPER MIXER MARKOCH}

Manual de Instruções

Modelo: 0710/01

Modelo: 0710/02

Parabéns, agora você possui um SUPER MIXER com alto padrão de eficiência e qualidade, garantindo sucesso no preparo de suas receitas.

Antes da utilização, leia atentamente as instruções de uso, pois o bom funcionamento de seu aparelho e a sua segurança dependem delas.

\section{LHO}

CARACTERÍSTICAS E ESPECIFICAÇÕES DE SEU APARE-

O SUPER MIXER MARKOCH apresenta:

- Botão Liga-Desliga + Pulsar

- Lâminas de alta performance

- Braço desmontável

- Gancho porta-fio

\section{ANTES DE UTILIZAR O SEU SUPER MIXER}

- Limpe o aparelho com um pano macio para não riscar o material de acabamento das superfícies.

- Desconecte o braço e lave com detergente neutro e água corrente. Cuidado com a limpeza das lâminas, pois elas são muito afiadas.

- Após a limpeza, seque completamente o produto.

- Toda a limpeza deverá ser feita com o produto desligado e desconectado da tomada.

COMO UTILIZAR O SEU SUPER MIXER

- Verifique se a voltagem do aparelho é a mesma da tomada a ser utilizada.

- Conecte o plugue na tomada. 
- Segure o aparelho pelo cabo anatômico e coloque-o dentro do recipiente com o alimento a ser preparado.

- Com o braço dentro da mistura, acione o botão liga-desliga.

- Caso a mistura seja muito espessa, aperte e solte o botão para acionar a função pulsar.

- Se desejar bater diretamente na panela, retire primeiramente o recipiente do fogo e deixe esfriar um pouco. Introduza primeiramente o braço na mistura e só depois acione o botão.

- Mantenha o botão pressionado durante a mistura e mova o aparelho para baixo e para cima e em forma circular, a menos que a receita indique outro movimento.

- Aperte e solte o botão em intervalos menores de 1 (um) minuto.

- Desligue o aparelho soltando o botão liga-desliga e, então, retire o braço da mistura.

- Primeiro processe os alimentos secos e só depois acrescente os líquidos.

\section{IMPORTANTE}

Não utilize seu aparelho por mais de 1 (um) minuto ininterruptamente. Após deixá-lo ligado por 1 minuto, deixe-o esfriar desligado por cerca de 5 (cinco) minutos, antes de utilizá-lo novamente. Após este intervalo, você poderá reutilizá-lo novamente, sempre observando o tempo máximo de utilização ininterrupta. Isso evitará superaquecimento e garantirá maior vida útil ao aparelho.

Nota:

Não utilize o Super Mixer em ingredientes ferventes para evitar respingos e queimaduras.

Não use o aparelho para cortar carne ou gelo.

Não utilize em massas pesadas e não faça o aparelho funcionar além da capacidade para a qual foi projetado.

\section{COMO LIMPAR O SEU SUPER MIXER}

- Retire o plugue da tomada antes de iniciar qualquer limpeza.

- Siga as instruções de limpeza do item ANTES DE USAR O SEU APARELHO.

- Não use jamais palhas de aço, buchas de esfregar ou qualquer espécie de limpadores e materiais abrasivos, pois eles podem danifi- 
car seu aparelho.

- Nunca mergulhe o corpo do aparelho na água.

RECOMENDACÕES E ADVERTÊNCIAS IMPORTANTES

Antes de utilizar o aparelho, leia atentamente todas as instruções de uso, pois elas são necessárias para um perfeito funcionamento de seu produto, e para sua segurança:

- Antes de ligar o plugue na tomada, verifique se a voltagem do aparelho é compatível com a da rede elétrica local.

- Este aparelho foi produzido para fins domésticos; sua utilização comercial acarretará a perda da garantia.

- Desligue o aparelho da tomada sempre que não estiver utilizando o mesmo.

- Para evitar choques elétricos, nunca use o aparelho com as mãos molhadas, não molhe o corpo do aparelho e não o mergulhe em água.

- Para evitar acidentes, não permita que crianças utilizem o produto ou mesmo pessoas que desconheçam suas instruções de uso.

- Sempre que colocar o aparelho de lado, mesmo que por breves instantes, desligue-o.

- Não utilize extensões auxiliares para aumentar o comprimento do cabo plugue.

- Nunca permita que o cabo plugue se encoste a superfícies quentes. gue.

- Nunca transporte ou desligue o produto puxando pelo cabo plu-

- Nunca use o produto com o cabo plugue ou plugue danificados, ou ainda se o produto apresentar mau funcionamento. Leve-o a uma Assistência Técnica Autorizada MARKOCH.

- Para não perder a garantia, evitar problemas técnicos e risco de acidentes ao usuário, não permita que sejam feitos consertos e/ou trocas de peças em casa; caso seja necessário, leve o produto a uma Assistência Técnica Autorizada MARKOCH.

O "Manual de Instruções SUPER MIXER MARKOCH” é um texto que acompanha o produto. Apresenta orientações ao leitor para o uso do aparelho e expõe o seu funcionamento. Diferencia-se por enfati- 
zar a ação e explicitá-la de forma detalhada.

Segundo Fávero e Koch (1998), esse gênero textual direciona comportamentos sequencialmente ordenados. Verbaliza um processo linear de observação, e a atenção se fixa no objeto.

O manual de instruções pertence à ordem do "descrever ações", pois indica ao interlocutor, de modo detalhado, as ações a serem seguidas para a utilização adequada do aparelho.

A tipologia textual de base é a injuntiva. De acordo com Travaglia (1991), a injunção põe em evidência as modalidades de ordem e prescrição. Assim, a função sócio-comunicativa do gênero em análise é instruir alguém a realizar algo. Pode-se, assim, incluí-lo na categoria dos textos injuntivos instrucionais-programadores.

Esse manual distingue-se fundamentalmente pelas formas verbais imperativas (limpe, desconecte, seque, verifique, conecte, segure, mantenha). Empregam-se ainda verbos no infinitivo (utilizar, acionar, desejar, bater, ligar, colocar, evitar) e no futuro do presente (deverá, poderá, evitará, garantirá, acarretará).

O gênero vale-se de uma linguagem comum, com o emprego de um conjunto de palavras, expressões e construções usuais. Utiliza uma sintaxe acessível ao leitor comum, ou seja, a linguagem é simples, mas segue o padrão da língua escrita. Para se dirigir ao leitor, emprega o pronome "você" implícito ("Não utilize extensões auxiliares para aumentar o comprimento do cabo plugue").

A estrutura do manual de instruções permite ao interlocutor encontrar facilmente as informações que deseja e lhe proporciona orientações claras e seguras, que possibilitam utilizar com sucesso o aparelho. O texto apresenta um título destacado (SUPER MIXER MARKOCH) que diz respeito ao nome e à marca do produto, seguido de um subtítulo (Manual de Instruções); na sequência, aparecem outros subtítulos que 
apontam as características e especificações do aparelho e os procedimentos a serem efetuados (Antes de utilizar o seu Super Mixer; Como utilizar o seu Super Mixer; Como limpar o seu Super Mixer; Recomendações e Advertências Importantes).

Na parte inicial, o texto apresenta uma lista dos elementos que serão manuseados no procedimento (lâminas, braço), seguida da exposição de algumas de suas características ("lâminas de alta performance", "braço desmontável"). O texto não utiliza desenhos para especificar os componentes do aparelho. No entanto, segundo Travaglia (1991), para substituir a descrição dos elementos, podem aparecer fotos ou desenhos com indicação dos nomes das partes, acompanhadas ou não da explicitação de sua função (Cf. TRAVAGLIA: 1991, p.293).

Em seguida, o manual de instruções expõe, em ordem cronológica, os procedimentos a serem efetuados antes de usar o Super Mixer. Na sequência, explicita detalhadamente como utilizar o aparelho e as ações a serem realizadas para a limpeza após o uso. No final do texto, aparecem conselhos importantes com o intuito de ajudar o comprador a usar corretamente o aparelho ("Antes de ligar o plugue na tomada verifique se a voltagem do aparelho é compatível com a da rede elétrica local"). Esses lembretes objetivam também evitar possíveis acidentes domésticos ("Para evitar choques elétricos, nunca use o aparelho com as mãos molhadas, não molhe o corpo do aparelho e não o mergulhe em água").

A progressão do sentido e a continuidade do texto ocorrem através de itens não numerados que apresentam, numa sequência cronológica, instruções a serem assimiladas e efetuadas pelo usuário. As sentenças começam por verbos que direcionam a ação do leitor e apontam aquilo que deve ou não ser feito (mantenha, aperte, desligue, retire, siga).

O texto emprega operadores argumentativos apropriados ao encadeamento de ações (antes, após, primeiramente, depois) a fim de permi- 
tir ao interlocutor a imediata compreensão da direção a ser seguida na concretização das instruções.

Verifica-se ainda a presença de vocábulos e expressões destacadas no texto (IMPORTANTE, Nota) que assinalam mensagens e avisos relevantes. $\mathrm{O}$ uso desse recurso objetiva resguardar o consumidor de riscos desnecessários ("Não utilize o Super Mixer em ingredientes ferventes para evitar respingos e queimaduras"). Também o orienta a utilizar adequadamente o aparelho adquirido ("Não utilize seu aparelho por mais de 1 (um) minuto ininterruptamente. [...] Isso evitará superaquecimento e garantirá maior vida útil ao aparelho").

O manual de instruções, portanto, guia o destinatário do texto no sentido de que realize uma macroação: utilizar o Super Mixer Markoch de forma correta e segura. Para isso, ele precisa executar um conjunto planejado de microações, especificadas no texto, como conectar o plugue do aparelho na tomada, segurá-lo pelo cabo anatômico e colocá-lo dentro do recipiente com o alimento a ser preparado.

Como se observa, esse texto injuntivo compõe-se de três etapas: exposição do macro-objetivo acional ("Antes da utilização, leia atentamente as instruções de uso"); apresentação dos comandos a serem efetuados (equivalem às microações) para a concretização desse macro-objetivo e explicitação da justificativa. O produtor ressalta porque o destinatário deve seguir as instruções indicadas no texto: "elas são necessárias para um perfeito funcionamento de seu produto, e para sua segurança".

\subsection{A receita culinária}

\section{DELÍCIA GELADA}

Ingredientes:

1 lata de leite condensado light

1 copo de iogurte natural

1 caixa de gelatina light - sabor de sua escolha $400 \mathrm{ml}$ de água 
Modo de Preparo:

Dissolva a gelatina na água, conforme instruções na caixa. Bata, utilizando o MIXER, a gelatina dissolvida, o leite condensado e o iogurte natural. Coloque o creme em recipientes individuais e leve para gelar. Quando estiver firme, está pronto para servir.

Sugestão: decore com uma fruta do sabor da gelatina. Você pode substituir o leite condensado por mais um pouco de iogurte natural para obter uma sobremesa mais saudável.

Categoria: sobremesas - doces

Esta receita: é light

Cozinha: brasileira

Temperatura: gelado

Dificuldade: fácil

Tempo de preparo: 15 min + o tempo de geladeira

Rendimento: 6 porções

(BERTIN: 2008, p. - adaptação das autoras)

A receita culinária "Delícia gelada" empregou a sequência injuntiva com o objetivo de orientar o interlocutor na preparação da sobremesa: descreve os ingredientes e define como executar a receita. Portanto, esse gênero textual pertence à ordem do "descrever ações".

A tipologia textual de base é a injunção, pois instrui seu interlocutor a fazer algo e indica-lhe as ações que deverão ser efetuadas através de verbos operacionais, em sua maioria, no imperativo (dissolva, bata, coloque, leve). Vale-se ainda de verbos no infinitivo (substituir, obter).

A função sócio-comunicativa da receita é ensinar alguém a realizar algo. É viável, portanto, enquadrar o gênero na categoria dos textos injuntivos instrucionais-programadores.

$\mathrm{O}$ texto tem como macro-objetivo acional instruir o leitor sobre o preparo de uma sobremesa, por meio de um plano de execução no qual 
há a exposição de cinco ações básicas (dissolver a gelatina e batê-la junto com o leite condensado e o iogurte natural; colocar o creme em recipientes, levá-lo para gelar e servi-lo) e duas ações opcionais (decorar a sobremesa e substituir o leite condensado por iogurte natural). Para que o leitor possa obter o resultado final almejado, deverá efetuar as ações básicas de acordo com a ordem processual hierárquica indicada. Entretanto, ele o fará se desejar. O produtor do texto não explicita a justificativa, ou seja, os motivos pelos quais o destinatário deve acatar a sequência de ações estabelecida.

Como se constata, essa receita conduz o interlocutor a efetuar uma macroação específica: preparar a sobremesa. Para isso, deverá realizar uma série de microações, que equivalem aos comandos. Verifica-se, assim, a presença de um núcleo transformacional que possibilita a passagem dos ingredientes não preparados (estado inicial) à sobremesa pronta (estado final).

Com o intuito de tornar o texto acessível ao seu interlocutor e mostrar-lhe com clareza como proceder para alcançar resultados satisfatórios, o gênero emprega uma linguagem comum e direta, com frases curtas e de fácil compreensão. Caracteriza-se pela objetividade, uma vez que deixa claro para o leitor as ações a serem executadas. Emprega orações na voz ativa, coordenadas em sua maioria: "coloque o creme em recipientes individuais e leve para gelar".

Para se dirigir ao leitor, o produtor utiliza um pronome de tratamento: "você pode substituir o leite condensado por mais um pouco de iogurte natural”. Contudo, na maioria das vezes, o pronome está implícito.

$\mathrm{Na}$ construção do texto, a coesão entre os diversos elementos que o compõem é garantida através de operadores argumentativos, sobretudo os de adição, que apontam uma sequência de ações (“e leve para gelar").

$\mathrm{O}$ vocabulário usado nesse gênero pertence ao campo semântico da 
culinária (gelatina light, gelar, leite condensado). Emprega adjetivos (natural, individual, saudável) e locuções adverbiais de lugar (na água, em recipientes) e instrumento (com o MIXER). Além disso, faz uso de abreviaturas para indicar quantidade e tempo: $\mathrm{ml}$ (mililitros), min (minuto).

A receita apresenta a seguinte estrutura: a) título: DELÍCIA GELADA (coerente com o texto); b) ingredientes: apresentados em forma de lista (leite condensado light, iogurte natural, gelatina light e água); especificam-se as quantidades necessárias através dos vocábulos "lata", "copo" e "caixa"; c) modo de fazer: coloca explicitamente o procedimento, ou seja, como se juntam os ingredientes para se alcançar o resultado final.

Existe uma coerência entre os ingredientes, o modo de fazer e os subtítulos presentes no texto.

O gênero coloca ainda duas sugestões ao leitor: a alternativa de decorar a sobremesa com uma fruta do sabor da gelatina e a possibilidade de substituir um dos ingredientes, o leite condensado, por outro mais saudável, o iogurte natural. Além disso, há informações complementares, indicando a categoria (sobremesas - doces), o tipo de receita (light), a cozinha a que pertence (brasileira), a temperatura do prato (gelado), o grau de dificuldade (fácil), o tempo de preparo (15 min + o tempo de geladeira) e o rendimento (6 porções).

\section{Considerações finais}

O trabalho de leitura e escrita a partir dos gêneros textuais pode ser uma saída para um ensino de língua mais eficiente, pois eles estão presentes na realidade cotidiana do aluno. Na medida em que concebemos os gêneros textuais como objetos flexíveis, maleáveis e disponíveis na sociedade, maiores e melhores expectativas se multiplicam para as aulas de português.

As atividades de leitura e de escrita de diferentes gêneros textu- 
ais e a compreensão de seus contextos comunicativos auxiliam na ampliação da autonomia linguística do estudante. Assim, a exploração de textos de tipologia de base injuntiva, como a receita e o manual de instruções, também é um caminho para desenvolver a criatividade e a capacidade crítica do aluno.

Com essas reflexões, esperamos contribuir com subsídios para a prática docente direcionada ao aperfeiçoamento das competências e habilidades necessárias para a recepção, sistematização e produção de textos. 


\section{Referências}

ADAM, J. M. Tipos de sequências textuais elementares. Tradução de Alexânia Ripoll et al. Revisão de Leci Borges Barbisan. Porto Alegre: Poligrafo, 1992.

BAKHTIN, M. Os gêneros do discurso. In: ------. Estética da criação verbal. São Paulo: Martins Fontes, 1992.

BERTIN, J. Delícia gelada. In: Mix de receitas especiais. Caxias do Sul: UCS, 2008.

BRASIL. Parâmetros Curriculares Nacionais: Ensino Médio. Brasília: Ministério da Educação, 1999.

BRONCKART, J. Atividade de linguagem, textos e discursos: por um interacionismo sociodiscursivo. Tradução de Anna Rachel Machado e Péricles Cunha.

São Paulo: EDUC, 1999.

FÁVERO, L. L. e KOCH, I. G. V. Lingüística textual: introdução. 4ed. São Paulo: Cortez Editora, 1998.

GERALDI, J. W. Portos de passagem. São Paulo: Martins Fontes, 1993.

MARCUSCHI, L. A.. Gêneros textuais: definição e funcionalidade. In: BEZERRA, M. A.; DIONISIO, A. P. e MACHADO, A. R. Gêneros textuais \& ensino. 2ed. Rio de Janeiro: Lucerna, 2002. p.19-36.

ROSA, A. L. T. No comando, a sequência injuntiva! In: DIONÍSIO, Â. P. e BEZERRA, N. S. Tecendo textos, construindo experiências. Rio de Janeiro: Lucerna, 2003.

SCHNEUWLY, B; DOLZ, J. et al. Gêneros orais e escritos na escola. Tradução de Roxane Rojo e Glaís Sales Cordeiro. Campinas: Mercado das Letras, 2004.

TRAVAGLIA, L. C. Um estudo textual-discursivo do verbo no português do Brasil. Tese de Doutoramento em Lingüística. Campinas: Universidade Estadual de Campinas, 1991. 